\title{
Integrating hydrodynamic model and Monte Carlo simulation for predicting extreme water levels in a river system
}

\author{
Wen-Cheng Liu * and Hong-Ming Liu
}

Department of Civil and Disaster Prevention Engineering, National United University, Miaoli, Taiwan

\begin{abstract}
Article history:
Received 26 October 2018

Revised 3 January 2019

Accepted 18 January 2019

\section{Keywords:}

Extreme water level, Hydrodynamic model, Monte Carlo, Joint probability, Model calibration and verification, Danshuei River system

\section{Citation:}

Liu, W.-C. and H.-M. Liu, 2019: Integrating hydrodynamic model and Monte Carlo simulation for predicting extreme water levels in a river system. Terr. Atmos. Ocean. Sci., 30, 589-604, doi: 10.3319/TAO.2019.01.18.01
\end{abstract}

\begin{abstract}
Estimates of extreme water level return periods in river systems are crucial for hydraulic engineering design and planning. Recorded historical water level data of Taiwan's rivers are not long enough for traditional frequency analyses when predicting extreme water levels for different return periods. In this study, the integration of a one-dimensional flash flood routing hydrodynamic model with the Monte Carlo simulation was used to predict extreme water levels in the Danshuei River system of northern Taiwan. The numerical model was calibrated and verified with observed water levels using four typhoon events. The results indicated a reasonable agreement between the model simulation and observation data. Seven parameters, including the astronomical tide and surge height at the mouth of the Danshuei River and the river discharge at five gauge stations, were adopted to calculate the joint probability and generate stochastic scenarios via the Monte Carlo simulation. The validated hydrodynamic model driven by the stochastic scenarios was then used to simulate extreme water levels for further frequency analysis. The design water level was estimated using different probability distributions in the frequency analysis at five stations. The design high-water levels for a 200-year return period at Guandu Bridge, Taipei Bridge, Hsin-Hai Bridge, Da-Zhi Bridge, and Chung-Cheng Bridge were 2.90, 5.13, $6.38,6.05$, and $9.94 \mathrm{~m}$, respectively. The estimated design water levels plus the freeboard are proposed and recommended for further engineering design and planning.
\end{abstract}

\section{INTRODUCTION}

There are total 132 river systems in Taiwan including 24 main rivers, 29 secondary rivers, and 79 ordinary rivers. The longest river is the Choshui River in Southern Taiwan. The river length is $186 \mathrm{~km}$ and channel slope reaches 1:46. Taiwan's rivers have the characteristics of short with steep slope and meandering. When heavy rainfall falls in the catchment area during typhoon events, the rivers are prone to overtopping resulting in flooding at midstream/downstream reaches. Extreme events cause heavy rainfall to be the main reason of flooding that is one of the worst natural hazards in Taiwan (Hsu et al. 2003; Hsieh et al. 2006). Typhoon Nari hit Taiwan in 16 - 21 September 2001 is one of an example to describe the extreme event. This typhoon brought torrential rainfall in mountainous areas where more than $1200 \mathrm{~mm}$ of rain fell over a two-day period, causing overbank flow in

\footnotetext{
* Corresponding author

E-mail:wcliu@nuu.edu.tw
}

many rivers. At least 94 people were killed and 10 others were listed as missing due to the strong typhoon. The Taipei Metro was severely damaged as a result of flooding, so it stopped for at least six months.

Extreme water levels in tidal rivers can cause overbanking and levee breaking, which results in economic and human life losses and social impacts. The water level in this type of transitional area is affected by upstream river flow, downstream tidal levels, and the operation of existing controllable structures (Zhong et al. 2016). Tidal rivers have negative impacts on surrounding areas where residents live, but these rivers also contribute several benefits. The astronomical tide at the mouth of tidal rivers obstructs fluvial flows flowing towards downstream reaches. The water level increases due to the interaction between tides and floods in tidal rivers (LeBlond 1978; Godin 1985). Moreover, it is vital to assess extreme water level frequency for flood risks and future flood defense designs.

There are two major approaches when determining 
extreme water levels depending on the availability of the observed water level data at a site. The first approach is a numerical simulation method. It can be used when there is not an adequate observational record for flooded water levels. A hydrodynamic model provides the link between the known statistics of the generating forces and the desired statistics of the water levels. These simulation methods, such as the joint probability method (Pugh and Vassie 1979; Tawn and Vassie 1989) and the Monte Carlo simulation (Svensson et al. 2013; Zhong et al. 2013), can be used to accurately predict extreme water levels. The second approach is a frequency analysis of annual maximum water levels that results from the combination of several forcing factors (Gumbel 1985; Sindhu and Unnikrishnan 2012). This approach can be used when reasonably long observation data (greater than 60 years) are available (Huang et al. 2008; Xu and Huang 2008). Xu and Huang (2011) used a 91-year data set at the Wusong station near Shanghai to calculate the 100-year annual maximum water level by means of general extreme value (GEV) model to plan coastal hazard mitigation in Yangtze Estuary. A 59year data set was also applied to examine the influence of a shorter data set on estimating 60-year annual maximum water level. The results revealed that model prediction using the 59-year data set resulted in underestimating the observed 60-year annual maximum water level.

According to the investigations by literature (Huang et al. 2008; Xu and Huang 2008), the frequency analysis is suitable for long observation data that were greater than 60 years. However, it is difficult to find long-term datasets greater than 60 years from gauge stations at Taiwanese river. Therefore, a traditional frequency analysis is not appropriate for gauge stations in Taiwan. The alternative numerical simulation method is suitable for analyzing extreme water levels. This method can be used to simulate extreme water levels using a hydrodynamic model driven by discharge upriver and tidal levels at the river mouth. The hydrodynamic model provides a link between a generating forcing with a return period and the expected extreme water levels. Mantz and Wakeling (1979) and Samuels and Burt (2002) used a very limited number of sampling scenarios, but they adopted accurate Monte Carlo simulations to produce a very large number of stochastic sampling scenarios. A simplified one-dimensional hydrodynamic model of the lower Rhine delta was applied to simulate extreme water levels. Zhong et al. (2013) established a joint probability analysis on astronomical tides, wind-induced storm surge, the Rhine flow and the Meuse flow at the river boundaries to produce a joint probability distribution. A one-dimensional hydrodynamic model was then applied to estimate high water-level frequencies in the estuary delta. The sampled Monte Carlo simulation method was used to generate a large number of stochastic scenarios as inputs for the one-dimensional hydrodynamic model.

The uncertainty of the evaluation procedure includes the determination of the influencing parameters, the data collection for the parameters, the establishment of parameter probability distribution, the cumulative probability of the parameters determined by the frequency analysis method, the application of the joint probability approach and Monte Carlo simulation to generate the scenarios, the scenario simulations using numerical model, and then the exceedance probability analysis.

The objective of this study is to integrate a one-dimensional flash flood routing hydrodynamic model with a Monte Carlo simulation to estimate extreme water levels in the Danshuei River system of northern Taiwan. The hydrodynamic model was first calibrated and verified with measured water levels using several typhoon events. The validated model was then applied to calculate water levels in the river system. Different water level scenarios at the downstream boundary and discharges at upstream boundaries were yielded from the Monte Carlo simulation to drive the hydrodynamic model. The desired extreme water levels with return periods of 50,100, and 200 years are proposed in this study. The current flood protection standard for the Danshuei River system is a 200 -year return period. This study uses uncertainty analysis and adds extreme events to the historical data to estimate the design water levels of the various river reaches under different return periods. The results of this research can provide a reference for government agencies to evaluate the design height of dike along the Danshuei River system.

\section{MATERIALS AND METHODS}

\subsection{Governing Equations of the Hydrodynamic Model}

The one-dimensional hydrodynamic model can be used to simulate during typhoon events, therefore the model is also called flash flood routing model. The hydrodynamic model consists of one-dimensional continuity and momentum equations which are based on a dynamic wave theory (i.e., Saint-Venant equations). The governing equations can be expressed as:

$$
\begin{aligned}
& \frac{\partial A}{\partial t}+\frac{\partial Q}{\partial x}=q_{1}-q_{2} \\
& \frac{\partial Q}{\partial t}+\frac{\partial}{\partial x}\left(\frac{Q^{2}}{A}\right)-g A\left(S_{0}-\frac{\partial Y}{\partial x}-S_{f}\right)=q_{1} V_{1}-q_{2}\left(\frac{Q}{A}\right)
\end{aligned}
$$

where $A$ represents the flow cross section area, $Y$ denotes the water depth, $Q$ marks the flow discharge, $g$ is the gravitational acceleration, $q_{1}$ is the lateral inflow per unit channel length, $q_{2}$ is the lateral outgoing overflow per unit channel length, $S_{0}$ is the channel bottom slope, $S_{f}$ is the friction slope that denotes energy loss per unit weight of fluid per unit length of channel, $V_{1}$ is the longitudinal velocity component 
of the lateral inflow, $t$ is time parameter, and $x$ is the spatial direction consistent with the flow direction. In governing Eqs. (1) and (2), there are only two variables, $Q$ and $Y$, to be solved by numerical method.

In this study, the four-point implicit finite difference method (Preissman 1961; Amein and Fang 1970) was used to solve for variables discharge $(Q)$ and water depth $(Y)$. The approach to treat the main stream and tributary at the confluence is that the water level must be equal (i.e., $\eta_{1}=\eta_{2}=\eta_{3}$, where $\eta$ is water level) and discharge must be balanced (i.e., $Q_{1}+Q_{2}=Q_{3}$ ) (see Fig. 1b). The detailed algorithms of the solution can be found in Fu et al. (2016) and Horvat et al. (2017).

\subsection{Frequency Analysis Methods}

A number of researchers have used frequency analyses to investigate extreme water levels (Gelder and Neykov 1998; Walton 2000; Sobey 2005). For example, the Federal Emergency Management Agency (FEMA) recommends the application of the GEV model to estimate extreme value of annual maxima for further planning coastal flood insurance along the west coast of the USA near the Pacific Ocean (FEMA 2005). Three distribution models including Gumbel, Weibull, and Frechet distributions are built into a model to form the three-parameter GEV model. A number of researchers have mentioned the application of GEV distributions that are represented by a shape factor parameter (Morrison and Smith 2002; De Michele and Salvadori 2005; $\mathrm{Xu}$ and Huang 2011). However, other types of probability distributions for frequency analyses can be justified to select the best distribution for extreme values. In this study, different types of distributions including the Gumbel, Weibull, Frechet, normal, lognormal, and log-Pearson 3 distributions were used to analyze extreme values.

The standard error (SE) and the correlation coefficient (CC) were used as indicators when evaluating the performance of each extreme value distribution (McKay et al. 1979). The most adaptive distribution (i.e., the lowest SE and the highest $\mathrm{CC}$ ) will be selected for further applications. The expressions for the SE and the CC are given as follows:

$S E=\sqrt{\frac{\sum_{i=1}^{n}\left(x_{i}-\hat{x}_{i}\right)^{2}}{n}}$

$C C=\frac{\sum_{i=1}^{n}\left(x_{i}-\bar{x}\right)\left(\hat{x}_{i}-\overline{\hat{x}}\right)}{\sqrt{\sum_{i=1}^{n}\left(x_{i}-\bar{x}\right)^{2}} \sqrt{\sum_{i=1}^{n}\left(\hat{x}_{i}-\overline{\hat{x}}\right)^{2}}}$

where $x_{i}$ represents the observed value, $\hat{x}_{i}$ represents the estimated value, $\bar{x}$ represents the mean of the sampling data, $\overline{\hat{x}}$ represents the mean of the estimated data, and $n$ represents the number of data.

\subsection{Monte Carlo Simulation}

Monte Carlo methods are a broad class of computational algorithms that rely on repeated random sampling to obtain numerical results. The essential idea is the use of randomness to solve problems that might be deterministic in principle. Monte Carlo simulations have been widely used in engineering for sensitivity analyses and quantitative probabilistic analyses in process design (Kroese et al. 2014). For example, they are applied in coastal flood damage estimates and coastal hydrodynamic modeling (De Moel et al. 2012; Camacho and Martin 2013; Lopeman et al. 2015; Höllt et al. 2015), flood propagation modeling (Van Bijnen et al. 2012; Zhou and Guo 2014; Dimitriadis et al. 2016), rainfall hyetograph design (Kottegoda et al. 2014), hydrological uncertainty analysis (Liu et al.2018), and water quality modeling (Martin and Ayesa 2010; Nakan and Haidary 2010; Jiang et al. 2013; Antanasijević et al. 2014).

The joint probability distribution may be identified based on the marginal distributions (the probability distributions of random variables) and their correlation. In the case that the random variables are independent to each other, their joint probability distribution function (PDF) is simply the multiplication of their PDF of random variables. In this step, the conditional distribution of random variables can be identified from the joint probability and marginal distributions. Based on this information, the Monte Carlo simulation can be implemented in the next step (Hawkes et al. 2002; Wang 2016).

In this study, the random variables are astronomical tides, surge heights, and river discharges at five upstream boundaries. A joint probability analysis of astronomical tides, surge heights, and river discharges at five upstream boundaries is established to produce a joint probability distribution of potential flood events. Then, importance sampling with the Monte Carlo simulation method is used to help generate a large number of stochastic scenarios as the inputs for the one-dimensional flash flood routing hydrodynamic model. A set of 6000 scenarios is generated from the Monte Carlo simulations to compute extreme water levels in a river system.

\subsection{Indices of the Hydrodynamic Simulation Performance}

To evaluate the performance of the one-dimensional flash flood routing hydrodynamic model, three criteria were used to compare the simulated results and the measured data: the mean absolute error (MAE), the root mean square error (RMSE), and the Nash-Sutcliffe coefficient (NS). The error indices can be defined by Eqs. (5), (6), and (7), respectively: 


$$
\begin{aligned}
& M A E=\frac{1}{N} \sum_{i=1}^{N}\left|H_{\text {sim }, i}-H_{m e s, i}\right| \\
& R M S E=\left[\frac{1}{N} \sum_{i=1}^{N}\left(H_{\text {sim }, i}-H_{\text {mes }, i}\right)^{2}\right]^{1 / 2} \\
& N S=1-\frac{\sum_{i=1}^{N}\left(H_{\text {sim }, i}-H_{\text {mes }, i}\right)^{2}}{\sum_{i=1}^{N}\left(H_{\text {mes }, i}-\overline{H_{\text {mes }}}\right)^{2}}
\end{aligned}
$$

where $H_{\text {mes }}$ represents the measured water level, $H_{\text {sim }}$ represents the simulated water level, $\overline{H_{m e s}}$, and $N$ represents the number of time measurements.

\section{INVESTIGATION AREA AND DATA DESCRIPTION}

\subsection{Description of Study Site}

The Danshuei River system covering three major tributaries, the Dahan River, the Xindian River, and the Keelung River is located in northern Taiwan (Fig. 1a). The watershed of the Danshuei River system occupies a population of over six million people (Liu et al. 2001). To prevent flooding in the Danshuei River system, the Erchung flood diversion channel, constructed near the confluence of the Dahan River and the Xindian River in 1984, was used to divert flood flow during typhoon events. The watershed area of the Danshuei River system is $2726 \mathrm{~km}^{2}$, with a mean annual precipitation of $3001 \mathrm{~mm}$. The total channel length is $327.6 \mathrm{~km}$ and the channel slope ranges from 1:37 to 1:6700. The dry season is from December to May, while the wet season is from June to November. Annual precipitation in the Dahan River, the Xindian River, and Keelung River is 2430, 3300, and $4000 \mathrm{~mm}$, respectively. The peak discharge of a 200-year flood reaches $25000 \mathrm{~m}^{3} \mathrm{~s}^{-1}$ (Water Resources Agency 2015). The major forcing mechanisms of flood flows are astronomical tides at the river mouth and river discharges at the upriver boundary. Semi-diurnal tides are represented by principal tidal constituents, with a mean tidal range of $2.21 \mathrm{~m}$ and a spring tidal range of $3.1 \mathrm{~m}$. The downstream reaches of all three tributaries are affected by tides (Hsu et al. 1999; Liu et al. 2004).

\subsection{Hydrodynamic Model Configuration}

In this study, the measured cross-sectional profiles at

(a)
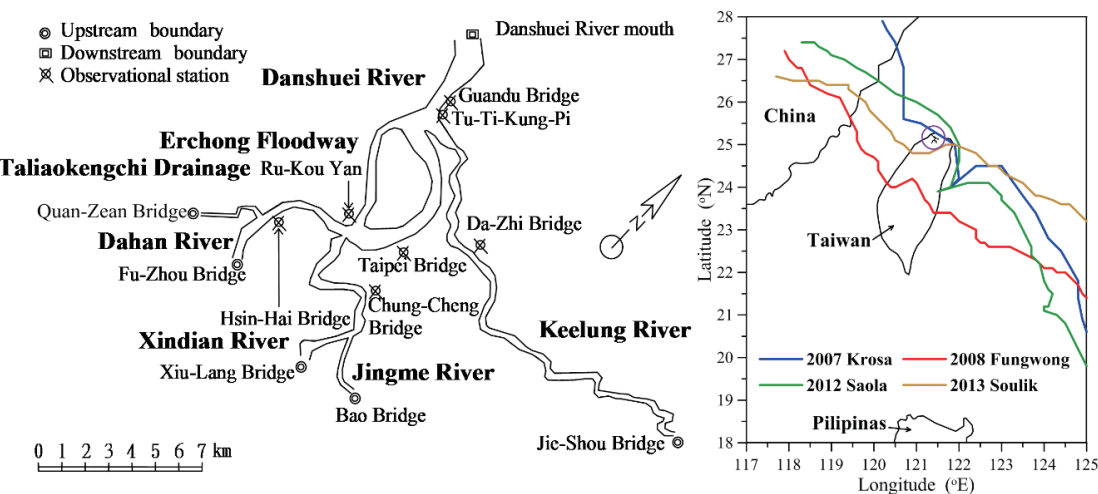

(b)

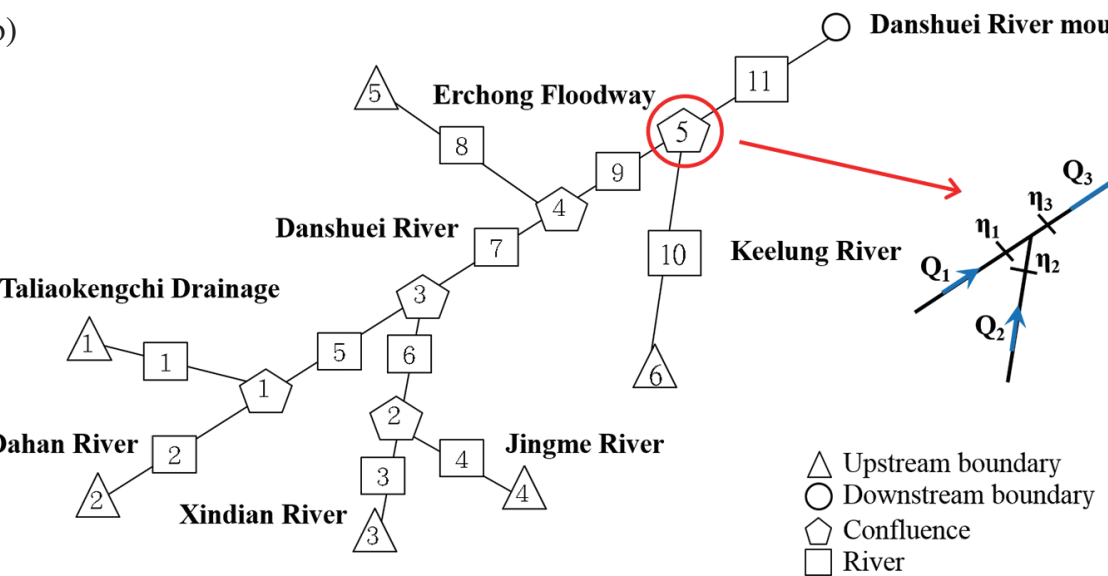

Fig. 1. (a) Map of the Danshuei River system in northern Taiwan and paths of the four typhoon events and (b) Layout of the Danshuei River system for the model simulation. 
approximately $0.5 \mathrm{~km}$ intervals along the river system were used to set up the model transects for model simulation. There are 310 model transects covering 11 river reaches in the computational domain (shown in Table 1). The downstream boundary is specified at the Danshuei River mouth. The upstream boundaries are located at Fu-Zhou Bridge, Quan-Zean Bridge, Xiu-Lang Bridge, Bao Bridge, and Jie-Shou Bridge (Fig. 1a). The upstream and downstream boundary conditions of the dynamic flood routing hydrodynamic model are represented by the hourly discharges and hourly tidal levels specified at the mouth of the Danshuei River, respectively (Fig. 1a). It means that the flood routing hydrodynamic model is run with unsteady flow conditions. The measured hourly discharges and hourly tidal level at the upstream and downstream boundary conditions during the typhoon events were observed and provided by the Water Resources Agency, Taiwan. The layout of the Danshuei River system for model simulation is illustrated in Fig. 1 b.

\subsection{Data Collection and Analysis}

Observational data, including tidal levels at the mouth of the Danshuei River and discharges upstream of the Taliaokengchi drainage, Dahan River, Xindian River, Jiangme River, and Keelung River, were collected from the Water Resource Agency of Taiwan. The data are shown in Table 2. Surge heights during typhoon periods were calculated as the difference between the observed tidal level and the astronomical tide. Observational data for astronomical tides, surge heights, and discharges were used to analyze and yield the probability of each parameter. To investigate the potential correlation between measured data, the surge heights and discharges were analyzed. The results reveal that the coefficients of determination $\left(\mathrm{R}^{2}\right)$ between surge heights and discharges at Fu-Zhou Bridge (Dahan River), between surge heights and discharges at Xiu-Lang Bridge (Xindian River), and between surge heights and discharges at Jie-Shou Bridge (Keelung River) are 0.66, 0.612, and 0.67 , respectively.

\section{MODEL CALIBRATION AND VERIFICATION}

To make sure the model accuracy for further practical applications, the observational data are used for model calibration and validation on simulating river water levels. In the one-dimensional hydrodynamic model, the important parameter is friction coefficient (n) that is to be determined based on the model calibration and verification procedures. The trial and error approach is used to tune the friction coefficient in the model. Two typhoons events, Typhoon Krosa (2007) and Typhoon Fungwong (2008), were used for the model calibration, and two other typhoon events, Typhoon Saola (2012) and Typhoon Soulik (2013), were used for model verification. The total rainfall in the Danshuei River basin for Typhoon Krosa, Typhoon Fungwong, Typhoon Saola, and Typhoon Soulik is 1813.5, 933.5, 2557.5, and $719.0 \mathrm{~mm}$, respectively, and the rainfall intensity for these four typhoons is $22.67,12.61,27.8$, and $11.06 \mathrm{~mm} \mathrm{hr}^{-1}$. The tracks of these typhoon events are illustrated in Fig. 1a. The Typhoon Nari (2001) was classified as extreme event which resulted in levee-break and overbank flows and caused severe damages in northern

Table 1. Cross-sectional number of river reaches and Manning coefficients $(n)$ used in the computational domain.

\begin{tabular}{c|cccccc}
\hline River reach number & 1 & 2 & 3 & 4 & 5 & 6 \\
Number of cross section & 71 & 8 & 3 & 13 & 9 & 22 \\
Manning friction $\boldsymbol{n}$ & 0.025 & 0.033 & 0.035 & 0.040 & 0.033 & 0.027 \\
\hline River reach number & 7 & 8 & 9 & 10 & 11 & \\
Number of cross section & 22 & 10 & 2 & 137 & 13 & \\
Manning friction $\boldsymbol{n}$ & 0.033 & 0.033 & 0.033 & 0.050 & 0.023 & \\
\hline
\end{tabular}

Table 2. Data description.

\begin{tabular}{c|ccc}
\hline Station & Data & Time & Data description \\
\hline Danhuei River mouth & Observed tidal level & $1994-2015$ & Hourly tidal level \\
Quan-Zean Bridge (Taliaokengchi Drainage) & Observed river discharge & $1994-2014$ & Daily-average discharge \\
Fu-Zhou Bridge (Dahan River) & Observed river discharge & $1994-2014$ & Daily-average discharge \\
Xiu-Lang Bridge (Xindian River) & Observed river discharge & $1994-2014$ & Daily-average discharge \\
Bao Bridge (Jingme River) & Observed river discharge & $1994-2014$ & Daily-average discharge \\
Jie-Shou Bridge (Keelung River) & Observed river discharge & $1994-2014$ & Daily-average discharge \\
\hline
\end{tabular}


Taiwan. Because the function to calculate levee-break and overbank flows was not considered in the governing Eqs. (1) and (2), Typhoon Nari (2001) was not selected as a case for model calibration and verification.

Figures 2 and 3 present the calibration results for Typhoon Krosa (2007) and Typhoon Fungwong (2008), respectively. Because of the data transmission system problem, the measured data from 13:00 to 18:00 on 6 October 2007 for Typhoon Krosa (2007) was lost. However, they indicate that the computed water level hydrograph is similar to the observed water level hydrograph. The mean absolute errors (MAEs) of the events at Taipei Bridge, Hsin-Hai Bridge, Da-Zhi Bridge, Chung-Cheng Bridge, Tu-Ti Kung $\mathrm{Pi}$, and Ru-Kou Yan (locations are shown in Fig. 1a) during Typhoon Krosa are 0.30, 0.30, 0.23, 0.22, 0.23, and $0.33 \mathrm{~m}$, respectively. In addition, the mean absolute errors (MAEs) of the events at Taipei Bridge, Hsin-Hai Bridge, Da-Zhi Bridge, Chung-Cheng Bridge, Tu-Ti Kung Pi, and Ru-Kou Yan during Typhoon Fungwong are 0.19, 0.15, 0.24, 0.22, 0.07 , and $0.18 \mathrm{~m}$, respectively. The lowest Nash-Sutcliffe coefficient (NS) is 0.76 at the Da-Zhi Bridge during Typhoon Fungwong (Table 3).

Figures 4 and 5 illustrate the verification results for Typhoon Saola (2012) and Typhoon Soulik (2013), respectively. These figures also reveal that the computed water levels mimic the observed water levels at different gauge stations. The MAEs of the events at Taipei Bridge, Hsin-Hai Bridge, Da-Zhi Bridge, Chung-Cheng Bridge, Tu-Ti Kung Pi, and Ru-Kou Yan during Typhoon Saola are 0.24, 0.06, 0.21, 0.11, 0.17 , and $0.40 \mathrm{~m}$, respectively. In addition, the MAEs of the events at Taipei Bridge, Hsin-Hai Bridge, Da-Zhi Bridge, Chung-Cheng Bridge, and Tu-Ti Kung Pi during Typhoon
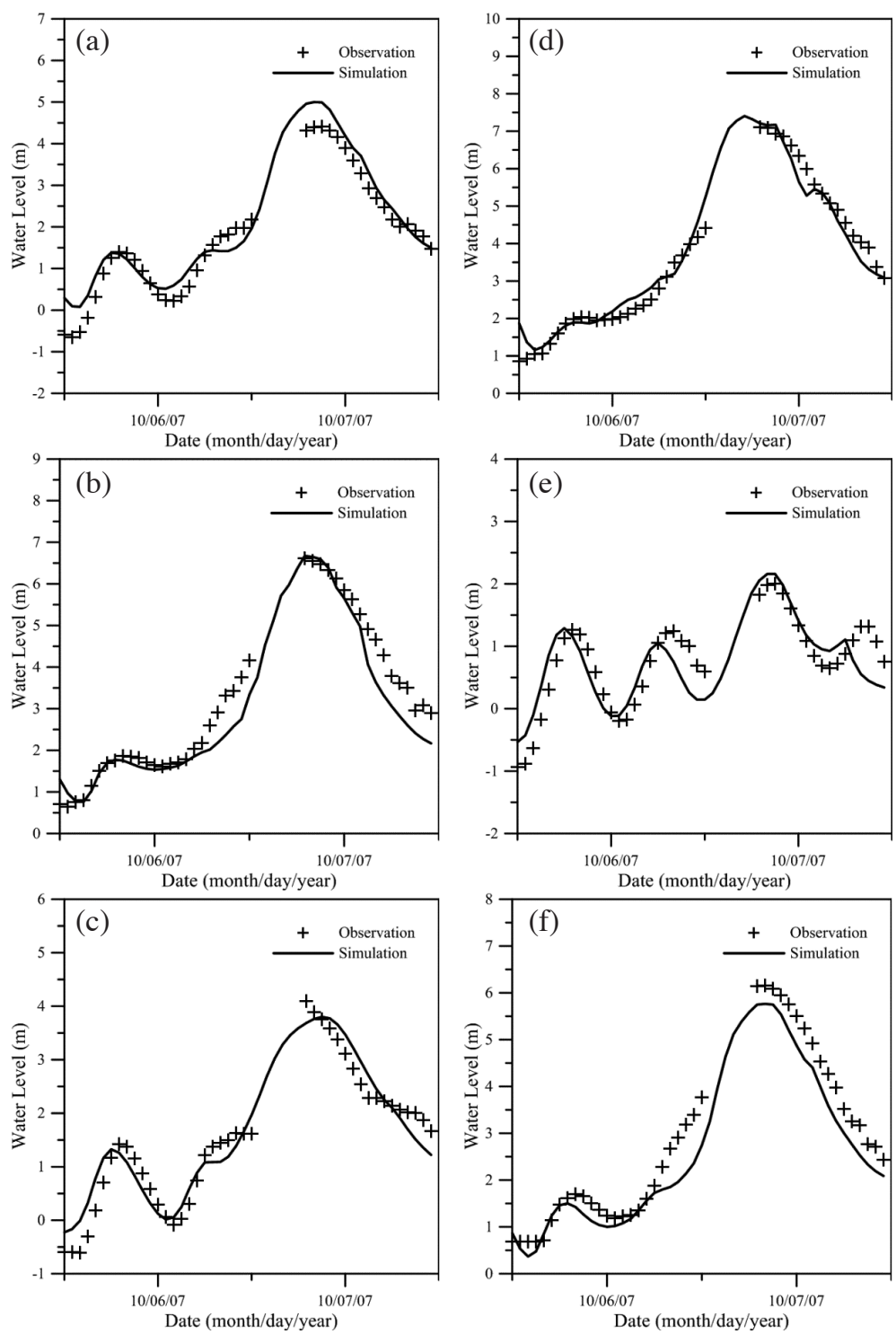

Fig. 2. Model calibration results for Typhoon Krosa (2007) at (a) Taipei Bridge, (b) Hsin-Hai Bridge, (c) Da-Zhi Bridge, (d) Chung-Cheng Bridge, (e) Tu-Ti-Kung-Pi, and (f) Ru-Kou Yan. 

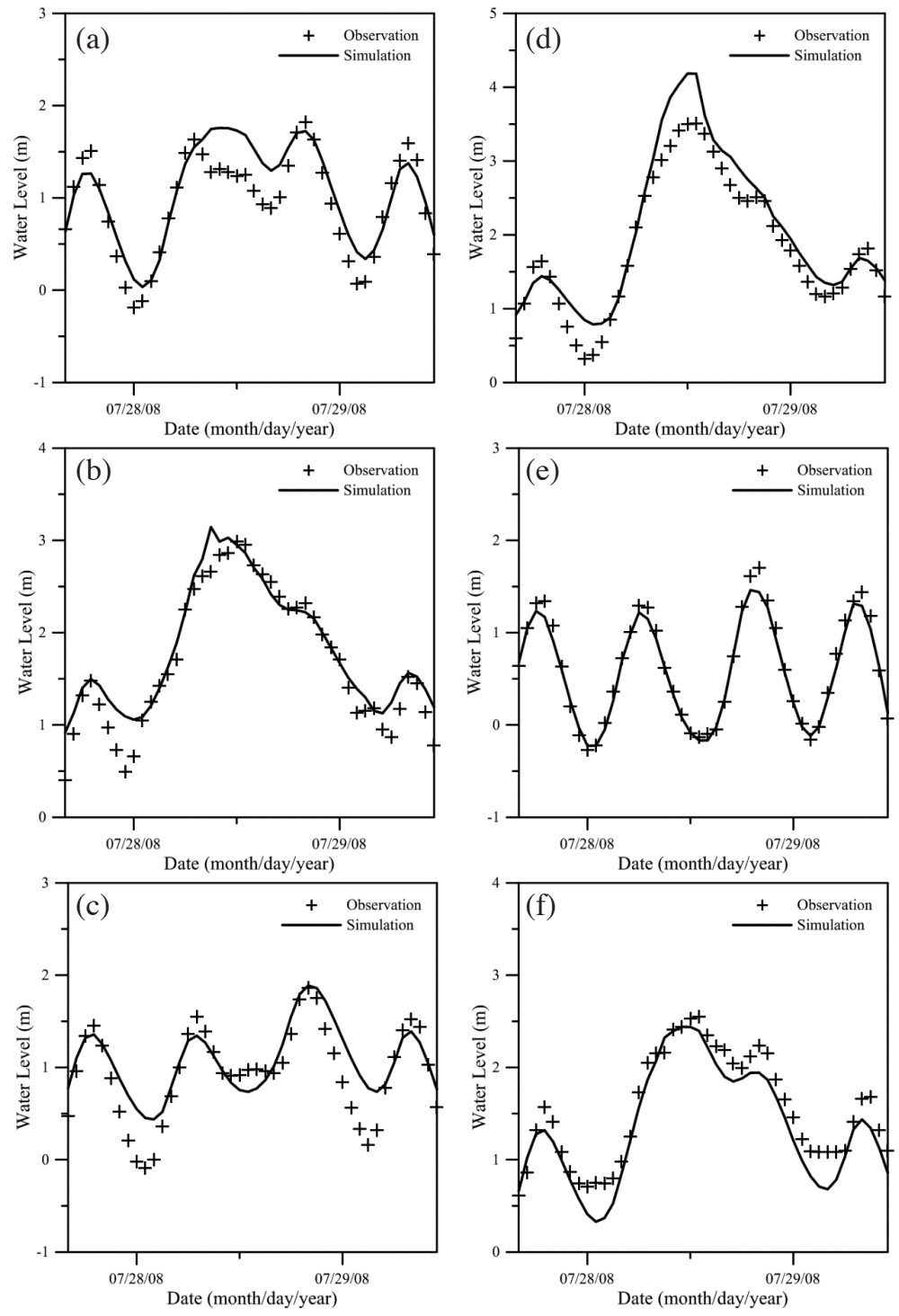

Fig. 3. Model calibration results for Typhoon Fungwong (2008) at (a) Taipei Bridge, (b) Hsin-Hai Bridge, (c) Da-Zhi Bridge, (d) Chung-Cheng Bridge, (e) Tu-Ti-Kung-Pi, and (f) Ru-Kou Yan.

Table 3. Statistical errors of the simulations using four typhoon events.

\begin{tabular}{|c|c|c|c|c|c|c|c|c|c|c|c|c|}
\hline \multirow[b]{2}{*}{ Station } & \multicolumn{3}{|c|}{ Typhoon Krosa } & \multicolumn{3}{|c|}{ Typhoon Fungwong } & \multicolumn{3}{|c|}{ Typhoon Saola } & \multicolumn{3}{|c|}{ Typhoon Soulik } \\
\hline & $\begin{array}{c}\text { MAE } \\
(\mathbf{m})\end{array}$ & $\begin{array}{c}\text { RMSE } \\
(\mathbf{m})\end{array}$ & NS & $\begin{array}{c}\text { MAE } \\
(\mathbf{m})\end{array}$ & $\begin{array}{c}\text { RMSE } \\
\text { (m) }\end{array}$ & NS & $\begin{array}{c}\text { MAE } \\
(\mathbf{m})\end{array}$ & $\begin{array}{c}\text { RMSE } \\
(\mathbf{m})\end{array}$ & NS & $\begin{array}{c}\text { MAE } \\
\text { (m) }\end{array}$ & $\begin{array}{c}\text { RMSE } \\
(\mathbf{m})\end{array}$ & NS \\
\hline Taipei Bridge & 0.30 & 0.37 & 0.92 & 0.19 & 0.24 & 0.80 & 0.24 & 0.29 & 0.96 & 0.19 & 0.24 & 0.94 \\
\hline Hsin-Hai Bridge & 0.30 & 0.42 & 0.94 & 0.15 & 0.21 & 0.91 & 0.06 & 0.08 & 0.99 & 0.18 & 0.21 & 0.97 \\
\hline Da-Zhi Bridge & 0.23 & 0.28 & 0.94 & 0.24 & 0.33 & 0.76 & 0.21 & 0.26 & 0.96 & 0.13 & 0.16 & 0.97 \\
\hline Chung-Cheng Bridge & 0.22 & 0.31 & 0.97 & 0.22 & 0.29 & 0.89 & 0.11 & 0.14 & 0.99 & 0.17 & 0.21 & 0.97 \\
\hline Tu-Ti Kung Pi & 0.23 & 0.28 & 0.82 & 0.07 & 0.10 & 0.97 & 0.17 & 0.22 & 0.93 & 0.10 & 0.12 & 0.98 \\
\hline Ru-Kou Yan & 0.33 & 0.42 & 0.93 & 0.18 & 0.21 & 0.88 & 0.40 & 0.44 & 0.92 & --- & --- & --- \\
\hline
\end{tabular}



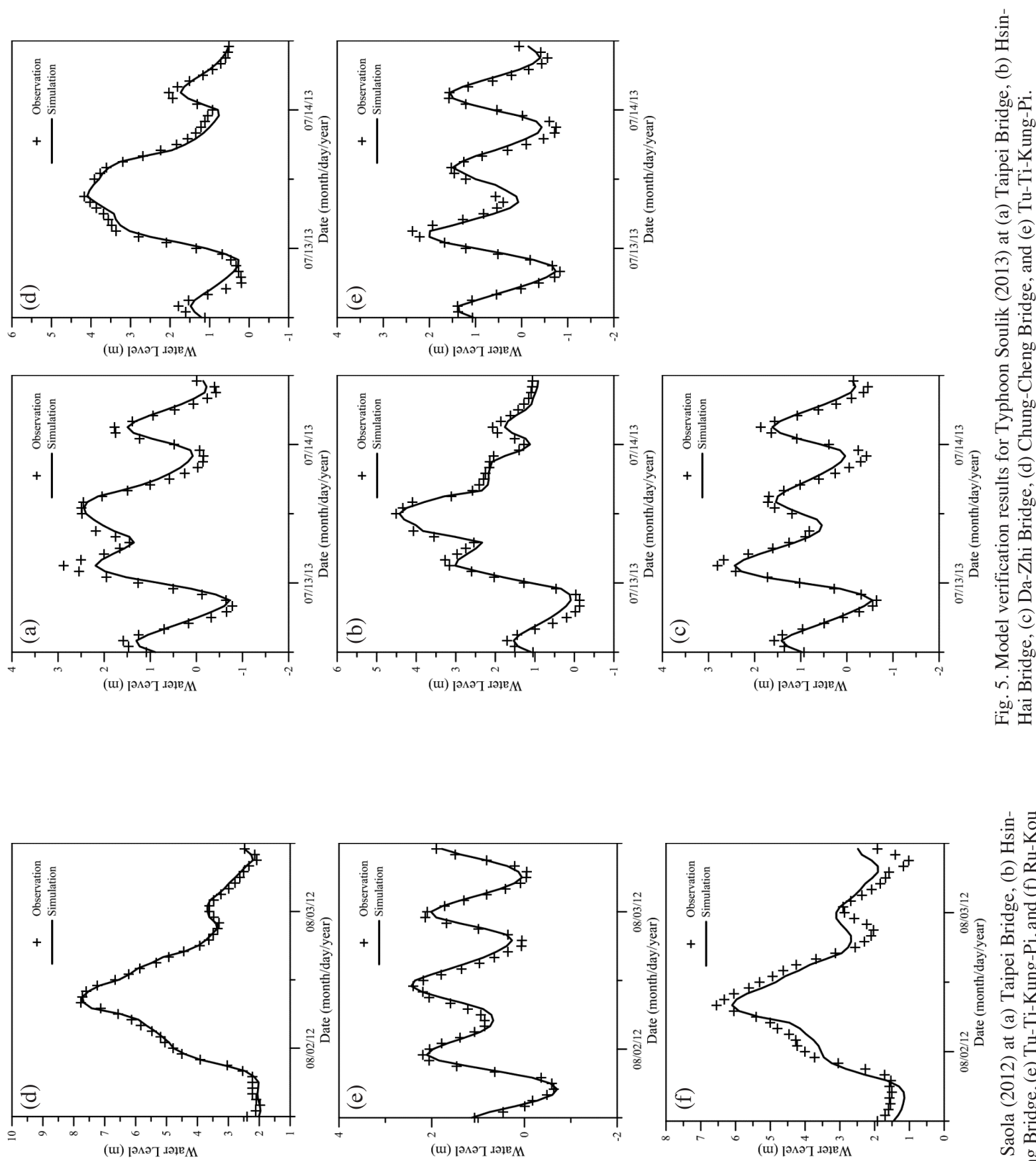

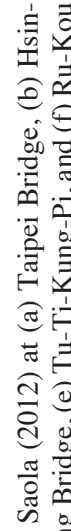
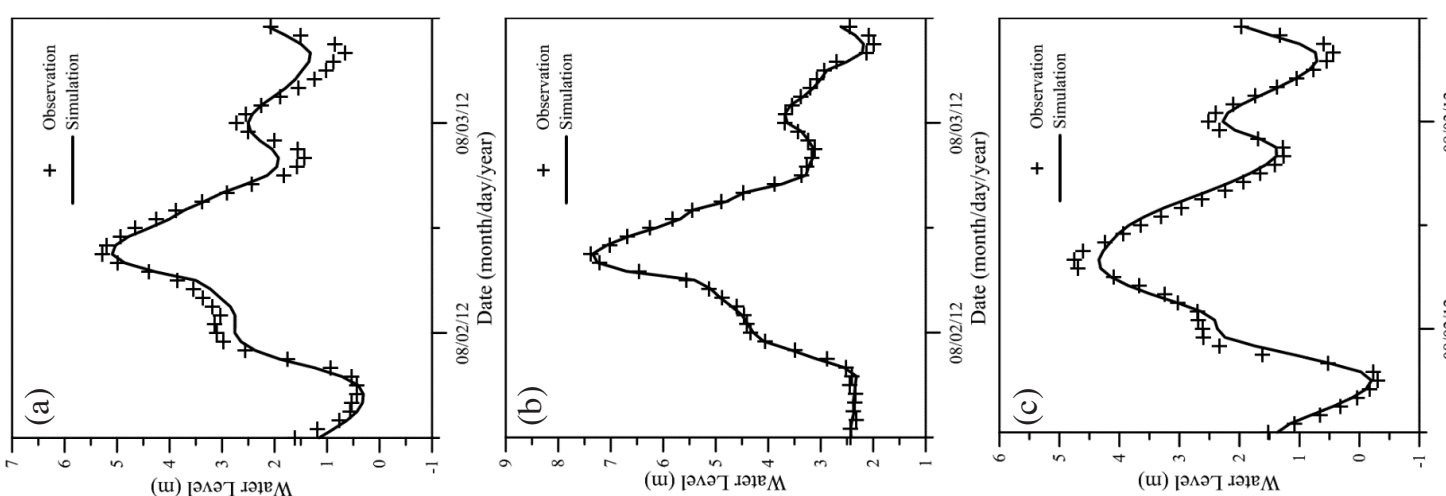

ธี ญ्ष

究占

总总

웅

造

.

氝

要

i

$\sum$ :

$\dot{\nabla}$

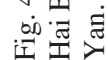


Soulik are $0.19,0.18,0.13,0.17$, and $0.10 \mathrm{~m}$, respectively. We found that the NS was higher than 0.90 for both Typhoon Saola and Typhoon Soulik (Table 3).

Table 3 presents the MAE, RMSE, and NS values at each station for the four typhoon events. It results show a reasonable agreement between the model predictions and the measured data. The Nash-Sutcliffe coefficient (NS) for these four typhoons is above 0.75 . Through the model calibration and verification procedures, the Manning friction coefficient (n) is determined and illustrated in Table 1. Table 1 indicates that because the upstream bed sediment is coarse particles from gravel to coarse sand, a higher Manning friction coefficient is used, and the downstream bed sediment is fine particles from fine sand to silt, so a lower Manning friction coefficient is used.

Domeneghetti et al. (2012) considered the overall uncertainty affecting river flow measurements and proposed a framework for analysis the uncertainty of rating-curve and its effects on the calibration of numerical hydraulic models. They highlighted the significant role of extrapolation errors and the rating-curve uncertainty was responsible for estimating unrealistic roughness coefficient. In the current study, the discharges at the gauge stations were collected from the Water Resources Agency, Taiwan. The discharge hydrograph at the gauge stations during typhoon events was calculated by converting measured water level into discharge by means of an existing stage-discharge rating curve. Using the ratingcurve to convert water levels into discharges inevitably introduces an additional source of uncertainty. However, the uncertainty of discharges at gauge stations during typhoon events has beyond the scope of this study. In the future work, we will focus on investigating the effect of rating-curve uncertainty on hydraulic model calibration.

\section{RESULTS AND DISCUSSION}

\subsection{Selecting the Best Distribution Function for the Statistical Parameters}

Based on the analysis of potential correlation between data described in section 2.4, seven parameters, including the astronomical tide and surge height at the mouth of the Danshuei River and the river discharges at the Quan-Zean Bridge, Fu-Zhou Bridge, Xiu-Lang Bridge, Bao Bridge, and Jie-Shou Bridge, are selected for the frequency analysis. The annual maximum for each parameter was adopted to establish the probability density function. The cumulative probability function of each parameter was then determined.

There are several methods used for the hydraulic engineering and hydrology to calculate the parameters in frequency analysis, such as L-moment, Maximum-Likelihood Estimation (MLE), and Markov Chain Monte Carlo (MCMC) (Hosking and Wallis 1997; Park et al. 2001; Su et al. 2009; Eastoe and Tawn 2010). FEMA (2005) recommended the method, Maximum-Likelihood Estimation
(MLE), for coastal extreme water level studies because MLE provides a consistent approach to parameter estimation and presents less bias than other methods. Therefore, the MLE is adopted to estimate optimal distribution parameters for different frequency analysis models in this study.

The predicted and observed cumulative probability function for each parameter is illustrated in Fig. 6. It shows the predicted cumulative probabilities using different frequency analysis methods, including the Gumbel, Weibull, Frechet, normal, lognormal, and log-Pearson 3 distributions. Two indices [i.e., the standard error (SE) and the correlation coefficient (CC)] were used to determine the optimal frequency analysis for each parameter. Table 4 shows statistics for the comparison between the predicted and observed cumulative probabilities for different frequency analysis methods. It indicates that the river discharges at the XiuLang Bridge and Bao Bridge are very high (Figs. 6e and f), causing the SE to be extremely high at these two stations.

The lowest SE and highest CC were selected as the best frequency analysis method. We found that the optimal frequency analysis methods were the lognormal distribution for surge height, the Weibull distribution for astronomical tide, the Weibull distribution for river discharge at the Quan-Zean Bridge (Taliaokengchi drainage), the lognormal distribution for river discharge at the Fu-Zhou Bridge (Dahan River), the log-Pearson 3 distribution for river discharge at the Xiu-Lang Bridge (Xindian River), the Weibull distribution for river discharge at Bao Bridge (Jingme River), and the Weibull distribution for river discharge at the Jie-Shou Bridge (Keelung River).

Zhong et al. (2013) found that the characteristics of high astronomical tide levels at the Hook of Holland could be captured in a normal distribution. The Gaussian copula function presented a dependent structure between the Rhine discharge and the Meuse discharge, where the marginal distributions fit a lognormal distribution for Rhine discharge and a Gamma distribution for Meuse discharge. The best fit for the frequency analysis method is based on the characteristics of each parameter. In this study, different frequency analysis methods including the Gumbel, Weibull, Frechet, normal, lognormal, and log-Pearson 3 distributions is used to obtain the optimal cumulative probability functions for each parameter. We found that the distribution models for the frequency analysis of astronomical tide and river discharge used in Zhong et al. (2013) were quite different from the distribution models adopted in our study.

\subsection{Integrating the Monte Carlo Simulation and the Hydrodynamic Model to Calculate Extreme Water Levels}

The joint probability of these seven parameters was used to generate different simulation scenarios. Six thousand scenarios based on the sampled Monte Carlo simulation were 

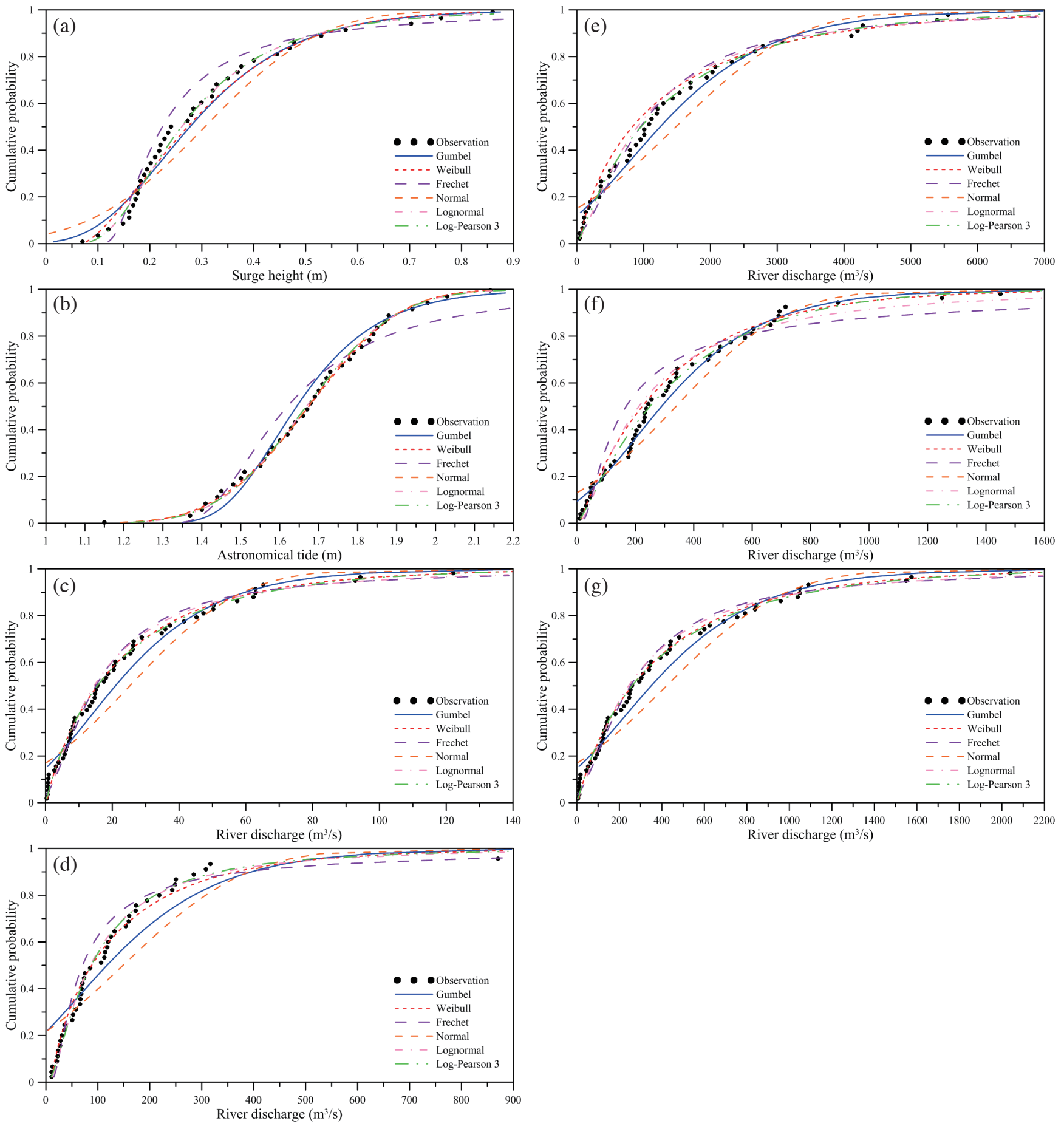

Fig. 6. Predicted and observed cumulative probability functions for each of the following parameters: (a) surge height at the mouth of the Danshuei River, (b) astronomical tide at the mouth of the Danshuei River, (c) river discharge at Quan-Zean Bridge (Taliaokengchi Drainage), (d) river discharge at Fu-Zhou Bridge (Dahan River), (e) river discharge at Xiu-Lang Bridge (Xindian River), (f) river discharge at Bao Bridge (Jingme River), and $(\mathrm{g})$ river discharge at Jie-Shou Bridge (Keelung River). 
Table 4. Statistical errors between the predicted and observed cumulative probability functions.

\begin{tabular}{|c|c|c|c|c|c|c|c|c|c|c|c|c|c|c|}
\hline \multirow{2}{*}{$\begin{array}{l}\text { Distribution } \\
\text { model }\end{array}$} & \multicolumn{2}{|c|}{ Surge height } & \multicolumn{2}{|c|}{$\begin{array}{l}\text { Astronomical } \\
\text { tide }\end{array}$} & \multicolumn{2}{|c|}{$\begin{array}{l}\text { River discharge } \\
\text { at Quan-Zean } \\
\text { Bridge }\end{array}$} & \multicolumn{2}{|c|}{$\begin{array}{c}\text { River discharge } \\
\text { at Fu-Zhou } \\
\text { Bridge }\end{array}$} & \multicolumn{2}{|c|}{$\begin{array}{c}\text { River discharge } \\
\text { at Xiu-Lang } \\
\text { Bridge }\end{array}$} & \multicolumn{2}{|c|}{$\begin{array}{l}\text { River discharge } \\
\text { at Bao Bridge }\end{array}$} & \multicolumn{2}{|c|}{$\begin{array}{c}\text { River discharge } \\
\text { at Jie-Shou } \\
\text { Bridge }\end{array}$} \\
\hline & $\begin{array}{l}\text { SE } \\
(m)\end{array}$ & $\mathrm{CC}$ & $\begin{array}{l}\text { SE } \\
(m)\end{array}$ & $\mathrm{CC}$ & $\begin{array}{c}\mathrm{SE} \\
\left(\mathrm{m}^{3} \mathbf{s}^{-1}\right)\end{array}$ & $\mathrm{CC}$ & $\begin{array}{c}\mathrm{SE} \\
\left(\mathbf{m}^{3} \mathbf{s}^{-1}\right)\end{array}$ & $\mathrm{CC}$ & $\begin{array}{c}\mathrm{SE} \\
\left(\mathbf{m}^{3} \mathbf{s}^{-1}\right)\end{array}$ & $\mathrm{CC}$ & $\begin{array}{c}\mathrm{SE} \\
\left(\mathrm{m}^{3} \mathbf{s}^{-1}\right)\end{array}$ & $\mathrm{CC}$ & $\begin{array}{c}\mathrm{SE} \\
\left(\mathbf{m}^{3} \mathbf{s}^{-1}\right)\end{array}$ & $\mathrm{CC}$ \\
\hline $\mathrm{Gu}$ & 0.0346 & 806 & 0.0397 & 0.9754 & 6.5460 & 0.9695 & 95.6662 & 0.8605 & 325.3179 & 0.9761 & 69.6968 & 0.9744 & 109.3666 & 0.9695 \\
\hline Weibull & 0.0323 & 0.9848 & 0.0128 & 0.9913 & 2.6015 & 0.9953 & $11 . / 004$ & 0.9354 & 321.7177 & 0.9849 & 49.0460 & 0.9895 & 43.4613 & 0.9953 \\
\hline Frechet & 0.1339 & 0.8880 & 0.2388 & 08410 & 10.2649 & 0.9617 & 96.7808 & 0.9557 & 455.4074 & 0.9613 & 945.5690 & 0.8449 & 171.4874 & 0.9617 \\
\hline Normal & 0.0663 & 0.9258 & 0.0138 & 0.9971 & 11.2177 & 0.9041 & 122.8602 & 0.7713 & 548.7033 & 0.9221 & 117.6550 & 0.9195 & 187.4202 & 0.9041 \\
\hline Lognormal & 0.0262 & 0.9901 & 0.0132 & 0.9974 & 7.1395 & 0.9795 & 61.7958 & 0.9578 & 403.8747 & 0.9718 & 143.3619 & 0.9739 & 119.2626 & 0.9795 \\
\hline Log-Pearson 3 & 0.0268 & 0.9889 & 0.0129 & 0.9975 & 2.7390 & 0.9952 & 68.8232 & 0.9532 & 200.0291 & 0.9911 & 49.0987 & 0.9866 & 45.7697 & 0.9952 \\
\hline
\end{tabular}

generated to drive the validated one-dimensional hydrodynamic model. The generated scenarios include hourly water levels at downstream boundary and hourly discharges at upstream boundaries for 24 hours. The Manning friction coefficients (n) in the one-dimensional hydrodynamic model were adopted as shown in Table 1. The one-dimensional hydrodynamic model was executed to yield simulated water levels which were further analyzed using frequency analysis.

Figure 7 presents the cumulative probability function of the simulated water level for different distribution methods at different stations in the Danshuei River including the Guandu Bridge, Taipei Bridge, Hsin-Hai Bridge, DaZhi Bridge, and Chung-Cheng Bridge. The Guandu Bridge is not the water level gauge station therefore there are no measured data of water level used for model calibration and verification. However the Guandu Bridge is an important landmark along the Danshuei River, thus the cumulative probability function of the simulated water level is also presented in Fig. 7a. Taking the Taipei Bridge as example, the water level at high tide during low and normal flow conditions is about 1.2 to $1.5 \mathrm{~m}$. When the water level is higher than $2 \mathrm{~m}$, it means that the Taipei Bridge is affected by high flow. Figure $7 \mathrm{~b}$ shows that a wide range of water levels are above $2 \mathrm{~m}$.

Table 5 shows statistics for the comparison between the predicted and observed cumulative probabilities at different stations for different frequency analysis methods. The results indicate that the optimal frequency analysis methods are the log-Pearson 3 distribution at Guandu Bridge, the lognormal distribution at Taipei Bridge, the lognormal distribution at Hsin-Hai Bridge, the lognormal distribution at Da-Zhi Bridge, and the Weibull distribution at ChungCheng Bridge.

Sindhu and Unnikrishnan (2012) estimated the different return periods of extreme events at 26 stations along the east coast of India based on annual maximum sea levels extracted from simulations using a vertically integrated two-dimensional model. The annual maximum sea level fit the Gumbel distribution using the r-largest annual maxima method. In our study, we found that the Gumbel distribution was not the best fit for water levels at the five stations.

\subsection{Potential Water Levels for Different Return Periods}

The design (extreme) water level is crucial for the design, construction, and maintenance of flood defense systems. According to the Taipei flood control system, the design water level in the Danshuei River system is regarded as the water level with an exceedance frequency of $1 / 200$ (i.e., a 200-year return period). Based on the cumulative probability function of water levels from the frequency analysis, the design water level for different return periods can be yielded. The equation for calculating the water level that corresponds to each return period can be given in Eq. (8):

$T=\frac{1}{1-F(x)}$

where $T$ represents the return period, and $F(x)$ is the cumulative probability function.

The design water level can be estimated using different probability distributions from the frequency analysis for different return periods at the five stations based on Eq. (8). Figure 8 presents the predicted water level for the different return periods at five stations. Table 6 shows the design water levels for the different return periods $(50,100$, and 200 years). The table indicates that the design water levels for the 200-year return period at Guandu Bridge, Taipei Bridge, Hsin-Hai Bridge, Da-Zhi Bridge, and Chung-Cheng Bridge are $2.90,5.13,6.38,6.05$, and $9.94 \mathrm{~m}$, respectively. It should be noted that the design water level should be added to the $1.5 \mathrm{~m}$ freeboard to result in a projected water level (Water Resources Agency 2011).

To avoid extremely high water-levels produced from these extreme events, the construction of new facilities in rivers needs exploration, and the present operational water management system requires adaptation in the future. 

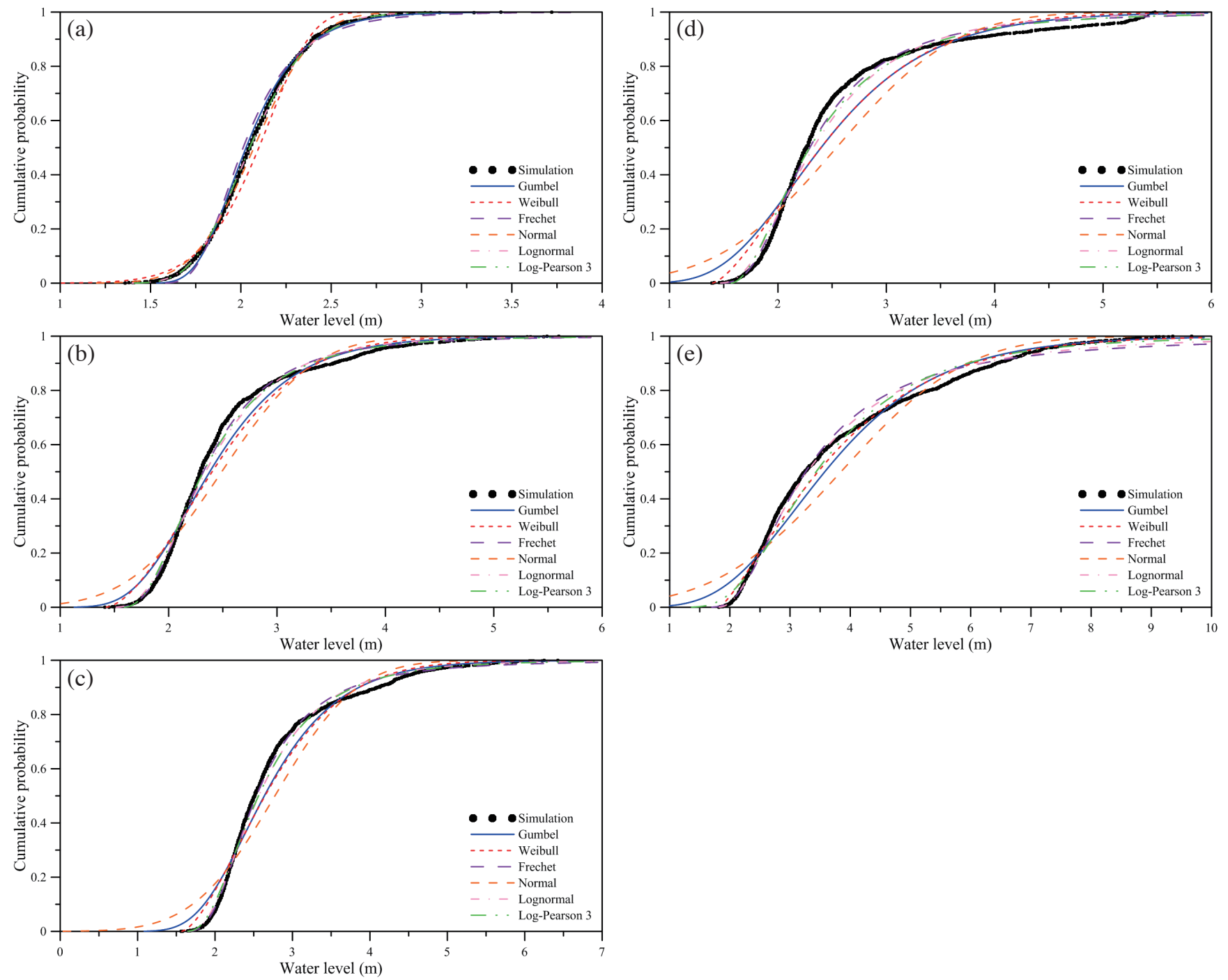

Fig. 7. Predicted and observed cumulative probability functions of the water level at (a) Guandu Bridge, (b) Taipei Bridge, (c) Hsin-Hai Bridge, (d) Da-Zhi Bridge, and (e) Chung-Cheng Bridge.

Table 5. Statistical errors between the predicted and observed cumulative probability functions at different stations.

\begin{tabular}{|c|c|c|c|c|c|c|c|c|c|c|}
\hline \multirow{2}{*}{$\begin{array}{c}\text { Distribution } \\
\text { model }\end{array}$} & \multicolumn{2}{|c|}{ Guandu Bridge } & \multicolumn{2}{|c|}{ Taipei Bridge } & \multicolumn{2}{|c|}{ Hsin-Hai Bridge } & \multicolumn{2}{|c|}{ Da-Zhi Bridge } & \multicolumn{2}{|c|}{ Chung-Cheng Bridge } \\
\hline & SE (m) & $\mathrm{CC}$ & SE (m) & $\mathrm{CC}$ & $\mathrm{SE}(\mathbf{m})$ & $\mathrm{CC}$ & SE (m) & $\mathrm{CC}$ & SE (m) & $\mathrm{CC}$ \\
\hline Gumbel & 0.0293 & 0.9939 & 0.1348 & 0.9796 & 0.1704 & 0.9789 & 0.2715 & 0.9504 & 0.3266 & 0.9800 \\
\hline Weibull & 0.0757 & 0.9583 & 0.1650 & 0.9694 & 0.1757 & 0.9783 & 0.2616 & 0.9542 & 0.2355 & 0.9897 \\
\hline Frechet & 0.0590 & 0.9800 & 0.1431 & 0.9778 & 0.3017 & 0.9494 & 0.3565 & 0.9209 & 1.7252 & 0.8140 \\
\hline Normal & 0.0416 & 0.9876 & 0.2771 & 0.9142 & 0.3428 & 0.9148 & 0.4296 & 0.8763 & 0.5832 & 0.9365 \\
\hline Lognormal & 0.0200 & 0.9972 & 0.1061 & 0.9888 & 0.1432 & 0.9852 & 0.2404 & 0.9627 & 0.7784 & 0.9318 \\
\hline Log-Pearson 3 & 0.0182 & 0.9976 & 0.1105 & 0.9864 & 0.1603 & 0.9817 & 0.2781 & 0.9494 & 0.4557 & 0.9645 \\
\hline
\end{tabular}




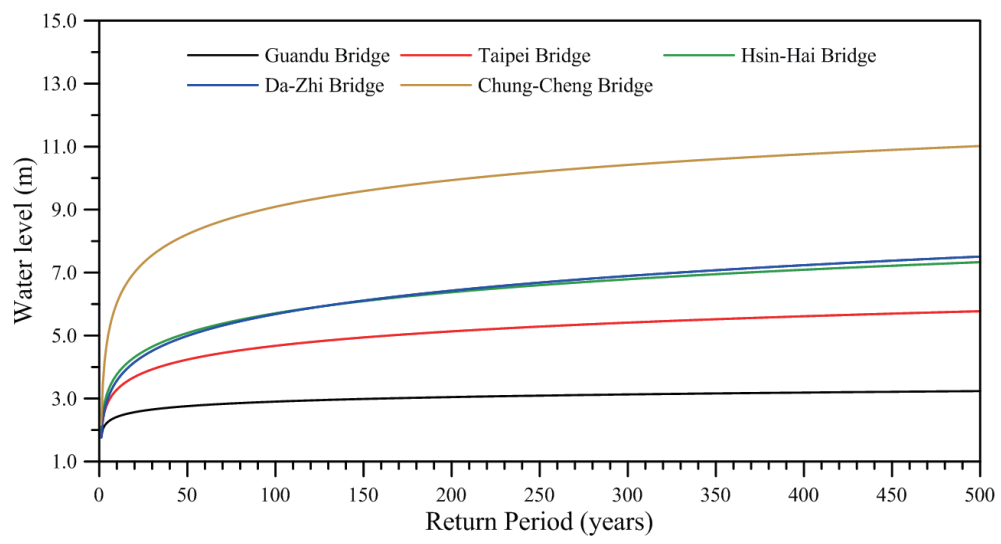

Fig. 8. Predicted water levels for different return periods at Guandu Bridge, Taipei Bridge, Hsin-Hai Bridge, Da-Zhi Bridge, and Chung-Cheng Bridge.

Table 6. Design water levels for different return periods.

\begin{tabular}{c|ccccc}
\hline Return Period & Guandu Bridge $(\mathbf{m})$ & Taipei Bridge $(\mathbf{m})$ & Hsin-Hai Bridge $(\mathbf{m})$ & Da-Zhi Bridge $(\mathbf{m})$ & Chung-Cheng Bridge $(\mathbf{m})$ \\
\hline 50 & 2.69 & 4.24 & 5.08 & 4.77 & 8.22 \\
100 & 2.80 & 4.68 & 5.71 & 5.39 & 9.09 \\
200 & 2.90 & 5.13 & 6.38 & 6.05 & 9.94 \\
\hline
\end{tabular}

\section{CONCLUSIONS}

Recorded historical water levels in the Danshuei River estuarine system of northern Taiwan are not sufficient to perform a traditional frequency analysis directly when predicting extreme water levels. The numerical simulation approach can be adopted when there is not an adequate amount of recorded historical data. This study presents extreme water levels simulated by a stochastic model, which is the integration of the Monte Carlo simulation and a one-dimensional flash flood routing hydrodynamic model. The hydrodynamic model was calibrated and verified with observational water levels using data from four typhoon events. The results indicated a reasonable agreement between the model predictions and recorded observations.

Seven parameters, including the astronomical tide and surge height at the mouth of the Danshuei River and river discharges at Quan-Zean Bridge, Fu-Zhou Bridge, XiuLang Bridge, Bao Bridge, and Jie-Shou Bridge, were selected for the frequency analysis. The joint probability of these seven parameters was used to produce a large set of stochastic scenarios, which were generated by via importance sampling of the Monte Carol simulation. Six thousand scenarios were generated to drive the validated hydrodynamic model simulations. The design water level was estimated using different probability distributions from the frequency analysis for different return periods at the five stations. We found that the design water levels for a 200-year return period at Guandu Bridge, Taipei Bridge, Hsin-Hai Bridge,
Da-Zhi Bridge, and Chung-Cheng Bridge were 2.90, 5.13, $6.38,6.05$, and $9.94 \mathrm{~m}$, respectively. The estimated design water levels plus the freeboard should be proposed and recommended for engineering design and planning.

In future research, recent typhoon events will be adopted for model calibration and verification to further make sure the model capability. The different statistical uncertainties and effects of uncertain boundary conditions must be investigated (Domeneghetti et al. 2013). One other issue is that the probability of failure for dikes in river systems should be further considered to understand flood risks (Rifai et al. 2017).

Acknowledgements This research was conducted as part of a grant supported by the Ministry of Science and Technology (MOST), Taiwan, grant No. 104-2625-M-239-002. The financial support is highly appreciated. The authors would like to express their appreciation to the 10th River Management Bureau, Water Resources Agency providing the measured data. Two anonymous reviewers are thanked for their constructive comments to substantially improve the paper.

\section{REFERENCES}

Amein, M. and C. S. Fang, 1970: Implicit flood routing in natural channels. Journal of the Hydraulics Division, 96, 2481-2500.

Antanasijević, D., V. Pocajt, A. Perić-Grujić, and M. Ristić, 
2014: Modelling of dissolved oxygen in the Danube River using artificial neural networks and Monte Carlo Simulation uncertainty analysis. J.Hydrol., 519, 18951907, doi: 10.1016/j.jhydrol.2014.10.009. [Link]

Camacho, R. A. and J. L. Martin, 2013: Bayesian Monte Carlo for evaluation of uncertainty in hydrodynamic models of coastal systems. J. Coast. Res., 65, 886-891, doi: 10.2112/SI65-150.1. [Link]

De Michele, C. and G. Salvadori, 2005: Some hydrological applications of small sample estimators of Generalized Pareto and extreme value distributions. J. Hydrol., 301, 37-53, doi: 10.1016/j.jhydrol.2004.06.015. [Link]

De Moel, H., N. E. M. Asselman, and J. C. J. H. Aerts, 2012: Uncertainty and sensitivity analysis of coastal flood damage estimates in the west of the Netherlands. Nat. Hazards Earth Syst. Sci., 12, 1045-1058, doi: 10.5194/ nhess-12-1045-2012. [Link]

Dimitriadis, P., A. Tegos, A. Oikonomou, V. Pagana, A. Koukouvinos, N. Mamassis, D. Koutsoyiannis, and A. Efstratiadis, 2016: Comparative evaluation of 1D and quasi-2D hydraulic models based on benchmark and real-world applications for uncertainty assessment in flood mapping. J. Hydrol., 534, 478-492, doi: 10.1016/j.jhydrol.2016.01.020. [Link]

Domeneghetti, A., A. Castellarin, and A. Brath, 2012: Assessing rating-curve uncertainty and its effects on hydraulic model calibration. Hydrol. Earth Syst. Sci., 16, 1191-1202, doi: 10.5194/hess-16-1191-2012. [Link]

Domeneghetti, A., S. Vorogushyn, A. Castellarin, B. Merz, and A. Brath, 2013: Probabilistic flood hazard mapping: Effects of uncertain boundary conditions. Hydrol. Earth Syst. Sci., 17, 3127-3140, doi: 10.5194/ hess-17-3127-2013. [Link]

Eastoe, E. F. and J. A. Tawn, 2010: Statistical models for overdispersion in the frequency of peaks over threshold data for a flow series. Water Resour. Res., 46, doi: 10.1029/2009WR007757. [Link]

Federal Emergency Management Agency (FEMA), 2005: Final Draft Guidelines for Coastal Flood Hazard Analysis and Mapping for the Pacific Coast of the United States.

Fu, J. C., M. H. Hsu, and Y. Duann, 2016: Development of roughness updating based on artificial neural network in a river hydraulic model for flash flood forecasting. J. Earth Syst. Sci., 125, 115-128, doi: 10.1007/s12040015-0644-z. [Link]

Gelder, P. V. and N. M. Neykov, 1998: Regional frequency analysis of extreme water levels along the Dutch coast using L-moments: A preliminary study. International Scientific Conference on Stochastic Models of Hydrological Processes and Their Applications to Problems of Environmental Preservation, Moscow, Russia, 1420.

Godin,G., 1985: Modification of river tides by the discharge.
Journal of Waterway, Port, Coastal, and Ocean Engineering, 111, 257-274, doi: 10.1061/(ASCE)0733950X(1985)111:2(257). [Link]

Gumbel, E. J., 1985: Statistics of Extreme, Columbia University Press, New York.

Hawkes, P. J., B. P. Gouldby, J. A. Tawn, and M. W. Owen, 2002: The joint probability of waves and water levels in coastal engineering design. J. Hydraul. Res., 40, 241-251, doi: 10.1080/00221680209499940. [Link]

Höllt, T., M. U. Altaf, K. T. Mandli, M. Hadwiger, C. N. Dawson, and I. Hoteit, 2015: Visualizing uncertainties in a storm surge ensemble data assimilation and forecasting system. Nat. Hazards, 77, 317-336, doi: 10.1007/s11069-015-1596-y. [Link]

Horvat, M., Z. Horvat, and B. Isic, 2017: Development, calibration and verification of a 1-D flow model for a looped river network. Environ. Model. Assess., 22, 6577, doi: 10.1007/s10666-016-9517-3. [Link]

Hosking, J. R. M. and J. R. Wallis, 1997: Regional Frequency Analysis: An Approach Based on L-Moments, Cambridge University Press, London, doi: 10.1017/ CBO9780511529443. [Link]

Hsieh, L. S., M. H. Hsu, and M. H. Li, 2006: An assessment of structural measures for flood-prone lowlands with high population density along the Keelung River in Taiwan. Nat. Hazards, 37, 133-152, doi: 10.1007/ s11069-005-4660-1. [Link]

Hsu, M. H., A. Y. Kuo, J. T. Kuo, and W. C. Liu, 1999: Procedure to calibrate and verify numerical models of estuarine hydrodynamics. J. Hydraul. Eng., 125, 166182, doi: 10.1061/(ASCE)0733-9429(1999)125:2(166). [Link]

Hsu, M. H., J. C. Fu, and W. C. Liu, 2003: Flood routing with real-time stage correction method for flash flood forecasting in the Tanshui River, Taiwan. J. Hydrol., 283, 267-280, doi: 10.1016/S0022-1694(03)00274-9. [Link]

Huang, W., S. Xu, and S. Nnaji, 2008: Evaluation of GEV model for frequency analysis of annual maximum water levels in the coast of United States. Ocean Eng., 35, 1132-1147, doi: 10.1016/j.oceaneng.2008.04.010. [Link]

Jiang, Y., Z. Nan, and S. Yang, 2013: Risk assessment of water quality using Monte Carlo simulation and artificial neural network method. J. Environ. Manage., 122, 130-136, doi: 10.1016/j.jenvman.2013.03.015. [Link]

Kottegoda, N. T., L. Natale, and E. Raiteri, 2014: Monte Carlo simulation of rainfall hyetographs for analysis and design. J. Hydrol., 519, 1-11, doi: 10.1016/j.jhydrol.2014.06.041. [Link]

Kroese, D. P., T. Brereton, T. Taimre, and Z. I. Botev, 2014: Why the Monte Carlo method is so important today. WIREs Comput. Statist., 6, 386-392, doi: 10.1002/ wics.1314. [Link] 
LeBlond, P. H., 1978: On tidal propagation in shallow rivers. J. Geophys. Res., 83, 4717-4721, doi: 10.1029/ JC083iC09p04717. [Link]

Liu, W. C., M. H. Hsu, and A. Y. Kuo, 2001: Investigation of long-term transport in Tanshui River estuary, Taiwan. Journal of Waterway, Port, Coastal, and Ocean Engineering, 127, 61-71, doi: 10.1061/(ASCE)0733950X(2001)127:2(61). [Link]

Liu, W. C., M. H. Hsu, C. R. Wu, C. F. Wang, and A. Y. Kuo, 2004: Modeling salt water intrusion in Tanshui River estuarine system-Case-study contrasting now and then.J.Hydraul.Eng., 130, 849-859, doi: 10.1061/ (ASCE)0733-9429(2004)130:9(849). [Link]

Liu, Z., S. Guo, L. Xiong, and C. Y. Xu, 2018: Hydrological uncertainty processor based on a copula function. Hydrolog. Sci. J., 63, 74-86, doi: 10.1080/02626667.2017.1410278. [Link]

Lopeman, M., G. Deodatis, and G. Franco, 2015: Extreme storm surge hazard estimation in lower Manhattan. Nat. Hazards, 78, 355-391, doi: 10.1007/s11069-0151718-6. [Link]

Mantz, P. A. and H. L. Wakeling, 1979: Forecasting flood levels for joint events of rainfall and tidal surge flooding using extreme value statistics. Proc. Inst. Civil Eng., 67, 31-50, doi: 10.1680/iicep.1979.2315. [Link]

Martin, C. and E. Ayesa, 2010: An integrated Monte Carlo methodology for the calibration of water quality models. Ecol. Model., 221, 2656-2667, doi: 10.1016/j.ecolmodel.2010.08.008. [Link]

McKay, M. D., R. J. Beckman, and W. J. Conover, 1979: A comparison of three methods for selecting values of input variables in the analysis of output from a computer code. Technometrics, 21, 239-245, doi: 10.2307/1268522. [Link]

Morrison, J. E. and J. A. Smith, 2002: Stochastic modeling of flood peaks using the generalized extreme value distribution. Water Resour. Res., 38, 41-1-41-12, doi: 10.1029/2001WR000502. [Link]

Nakan, K. and A. Haidary, 2010: Sensitivity analysis of stream water quality and land cover linkage models using Monte Carlo method. Int. J. Environ. Res., 4, 121130, doi: 10.22059/IJER.2010.161. [Link]

Park, J. S., H. S. Jung, R. S. Kim, and J. H. Oh, 2001: Modelling summer extreme rainfall over the Korean peninsula using Wakeby distribution. Int. J. Climatol., 21, 1371-1384, doi: 10.1002/joc.701. [Link]

Preissman, A., 1961: Propagation of translatory waves in channels and rivers. Proceedings 1st Congress of French Association for Computation, Grenoble, France, 433-442.

Pugh, D. T. and J. M. Vassie, 1979: Extreme sea levels from tide and surge probability. In Proceedings of the 16th International Conference on Coastal Engineering, Hamburg, Germany, American Society of Civil Engineers,
911-930, doi: 10.1061/9780872621909.054. [Link]

Rifai, I., S. Erpicum, P. Archambeau, D. Violeau, M. Pirotton, K. El Kadi Abderrezzak, and B. Dewals, 2017: Overtopping induced failure of noncohesive, homogeneous fluvial dikes. Water Resour. Res., 53, 33733386, doi: 10.1002/2016WR020053. [Link]

Samuels, P. G. and N. Burt, 2002: A new joint probability appraisal of flood risk. Water Marit. Eng., 154, 109115, doi: 10.1680/wame.2002.154.2.109. [Link]

Sindhu, B. and A. S. Unnikrishnan, 2012: Return period estimates of extreme sea level along the east coast of India from numerical simulations. Nat. Hazards, 61, 1007-1028, doi: 10.1007/s11069-011-9948-8. [Link]

Sobey, R. J., 2005: Extreme low and high water levels. Coast. Eng., 52, 63-77, doi: 10.1016/j.coastaleng.2004.09.003. [Link]

Su, B., Z. W. Kundzewicz, and T. Jiang, 2009: Simulation of extreme precipitation over the Yangtze River Basin using Wakeby distribution. Theor. Appl. Climatol., 96, 209-219, doi: 10.1007/s00704-008-0025-5. [Link]

Svensson, C., T. R. Kjeldsen, and D. A. Jones, 2013: Flood frequency estimation using a joint probability approach within a Monte Carlo framework. Hydrolog. Sci. J., 58, 8-27, doi: 10.1080/02626667.2012.746780. [Link]

Tawn, J. A. and J. M. Vassie, 1989: Extreme sea levels; The joint probabilities method revisited and revised. Proc. Instn Civ. Engrs, 87, 429-442, doi: 10.1680/iicep.1989.2975. [Link]

Van Bijnen, M., H. Korving, and F. Clemens, 2012: Impact of sewer condition on urban flooding: An uncertainty analysis based on field observations and Monte Carlo simulations on full hydrodynamic models. Water Sci. Technol., 65, 2219-2227, doi: 10.2166/wst.2012.134. [Link]

Walton, T. L., 2000: Distributions for storm surge extremes. Ocean Eng., 27, 1279-1293, doi: 10.1016/S00298018(99)00052-9. [Link]

Wang, C., 2016: A joint probability approach for coincidental flood frequency analysis at ungauged basin confluences. Nat. Hazards, 82, 1727-1741, doi: 10.1007/ s11069-016-2265-5. [Link]

Water Resources Agency, 2011: Flood disaster prevention business plan. Water Resource Agency, Ministry of Economic Affairs.

Water Resources Agency, 2015: Long-term hydrodynamic survey and flood forecasting in the Danshuei River system. Water Resource Agency, Ministry of Economic Affairs.

$\mathrm{Xu}, \mathrm{S}$. and W. Huang, 2008: Frequency analysis for predicting $1 \%$ annual maximum water levels along Florida coast, US. Hydrol. Process., 22, 4507-4518, doi: 10.1002/hyp.7051. [Link]

$\mathrm{Xu}, \mathrm{S}$. and W. Huang, 2011: Estimating extreme water levels with long-term data by GEV distribution at 
Wusong station near Shanghai city in Yangtze Estuary. Ocean Eng., 38, 468-478, doi: 10.1016/j.oceaneng.2010.11.022. [Link]

Zhong, H., P. J. van Overloop, and P. H. A. J. M. van Gelder, 2013: A joint probability approach using a 1-D hydrodynamic model for estimating high water level frequencies in the Lower Rhine Delta. Nat. Hazards Earth Syst. Sci., 13, 1841-1852, doi: 10.5194/ nhess-13-1841-2013. [Link]

Zhong, H., P. van Gelder, W. Wang, G. Wang, Y. Liu, and
S. Niu, 2016: The influence of statistical uncertainty in the hydraulic boundary conditions on the probabilistically computed high water level frequency curve in the Rhine Delta. Water, 8, 147, doi: 10.3390/w8040147. [Link]

Zhou, Y. and S. Guo, 2014: Risk analysis for flood control operation of seasonal flood-limited water level incorporating inflow forecasting error. Hydrolog. Sci. J., 59, 1006-1019, doi: 10.1080/02626667.2014.901515. [Link] 